\title{
Correction to: An Exploratory Study on Kidnapping as an Emerging Crime in Nigeria
}

\author{
Alaba M. Oludare, Ifeoma E. Okoye, \\ and Lucy K. Tsado
}

\section{Correction to:}

Chapter 5 in: H. C. O. Chan, S. Adjorlolo (eds.), Crime, Mental Health and the Criminal Justice System in Africa, https://doi.org/10.1007/978-3-030-71024-8_5

The original chapter was inadvertently published with incorrect affiliation of one of the authors 'Ifeoma E. Okoye'. The affiliation has been corrected in the chapter as below:

I. E. Okoye

Department of Criminal Justice, West Virginia State University, Institute, WV, USA

Changed to:

I. E. Okoye

Department of Criminal Justice, Virginia State University, VA, USA 